\title{
Reproductive Health Services and Intimate Partner Violence: Shaping a Pragmatic Response In Sub-Saharan Africa
}

Like it or not, the intersection of violence and reproductive decision-making is showing up in the realities of women's lives. Both movements had better organize to confront it. ${ }^{1}$

More than a decade ago, Lori Heise and other advocates against intimate partner violence highlighted the urgent need for stronger links between their cause and the reproductive health movement. Since then, the magnitude and implications of violence against women have gained more attention, leading to greater recognition and acknowledgment of the negative consequences of violence for women's reproductive health.

At the national policy level, however, violence and reproductive health often remain distinct, despite the framing of both issues as essential components of women's human rights and the growing evidence connecting them. ${ }^{2}$ In particular, linkage is generally inadequately addressed at the service level: Services that explicitly address violence against women are seldom integrated into women's reproductive health services, and there are few initiatives to integrate reproductive health services into a multisectoral response to violence against women. ${ }^{3}$

In this comment, we examine the context of intimate partner violence in Sub-Saharan Africa, outline the intersections between partner violence and reproductive health, and consider the opportunities for linkage at the program and service levels. In addition, we explore the opportunities and challenges related to developing an active response to domestic violence within reproductive health services in SubSaharan Africa.

\section{PREVALENCE OF INTIMATE PARTNER VIOLENCE}

One of the most common forms of violence against women is that perpetrated by a husband or other intimate male partner. Intimate partner violence-often called domestic violence-takes a variety of forms, including physical violence (e.g., slaps, punches, kicks, assaults with a weapon and homicide) and sexual violence (e.g., unwanted sexual touching, forced or coerced sex, or forced participation in degrading sexual acts). Violence is commonly accompanied by emotional abuse, economic restrictions and other controlling behaviors. ${ }^{4}$

Several population-based surveys from around the world have explored the prevalence of intimate partner violence. In these, women are asked directly about their experiences of specific acts of violence (for example, "Has a current or former partner ever hit you with his fist or with something else that could hurt you?"). ${ }^{5}$ Globally, $16-50 \%$ of ever- partnered women report having been physically assaulted by an intimate partner. ${ }^{6}$ In Sub-Saharan Africa, 13-49\% of women have ever been hit or otherwise physically assaulted by an intimate male partner, with 5-29\% reporting physical violence in the year before the survey. ${ }^{7}$

Research also suggests that many women are sexually assaulted by their partners. Cross-sectional household surveys in one province in Zimbabwe and in Ethiopia find that $26 \%$ and $59 \%$, respectively, of ever-partnered women have ever been forced to have sex, with $20 \%$ and $40 \%$ reporting unwanted sex in the year before the survey. ${ }^{8}$ The level of overlap between physical and sexual violence differs: Some men are physically violent only, some are sexually violent only and some are both physically and sexually violent. ${ }^{9}$

Research is also illustrating the extent to which women are physically assaulted during pregnancy. For some women who experience violence during pregnancy, the abuse is a continuation or intensification of previous abuse, whereas for others, the violence starts after they become pregnant. Ten percent of ever-pregnant women in Zimbabwe and at least 7\% in South Africa have ever been physically assaulted during pregnancy. ${ }^{10}$ In Butajira, Ethiopia, 77\% of currently pregnant women report physical abuse during pregnancy; $28 \%$ have been punched or kicked in the abdomen. ${ }^{11}$ In the great majority of cases, the perpetrator is the father of the child.

Although these figures give an indication of the magnitude of partner violence, differences between countries and sites have to be interpreted with caution. Such differences may represent not only actual differences by setting in the prevalence of violence, but also differences in research methodology, definitions of violence, sampling techniques, interviewer training and skills, and cultural differences that affect a respondent's willingness to reveal intimate experiences. ${ }^{12}$

\section{EFFECTS OF VIOLENCE ON REPRODUCTIVE HEALTH}

In many countries, violence against women is still predominantly perceived as a legal or human rights issue. Yet, such violence has wide-ranging health consequences. Although national data are scarce, a number of small-scale, community-based studies indicate that intimate partner violence is an important cause of morbidity and mortality, ${ }^{13}$ and an important factor affecting women's reproductive health. ${ }^{14}$ Forced sex is associated with a range of gynecological and reproductive health problems, including HIV and other sexually transmitted infections (STIs), unwanted pregnancy, vaginal bleeding or infection, fibroids, decreased sexual desire, genital irritation, pain during inter-
By Charlotte Watts and Susannah Mayhew

Charlotte Watts is senior lecturer in epidemiology and health policy, Health Policy Unit, Department of Public Health and Policy, and Susannah Mayhew is lecturer in reproductive health and health policy, Centre for Population Studies, Department of Epidemiology and Population Health, both with the London School of Hygiene and Tropical Medicine. 
course, chronic pelvic pain and urinary tract infections. ${ }^{15}$ Studies have linked abuse to unwanted pregnancies, especially among adolescent females, ${ }^{16}$ and violence greatly limits married women's ability to use contraceptives. ${ }^{17}$ Furthermore, a history of domestic violence is commonly found to be more prevalent in families with many children. ${ }^{18} \mathrm{Al}$ though it has been suggested that elevated violence may be associated with the stresses of large families, data from Nicaragua suggest that the onset of abuse generally precedes having children. ${ }^{19}$

Even when physical violence is not used to control a

To ensure that

women are not

further victim-

ized orblamed

during the

process of

consultation

and disclosure,

reproductive

health staff

must first con-

front their own

biases, miscon-

ceptions and

fears about

violence against

women. woman's behavior, the fear of violence may greatly influence her sexual and reproductive decision-making. In South Africa, for example, 57\% of women living in the Eastern Cape believe that they cannot refuse sex with their partner. ${ }^{20}$ The fear of violence is commonly cited by married women as a barrier to using condoms with their husbands for STI or pregnancy prevention. ${ }^{21}$ For many women in SubSaharan Africa, the withdrawal (or threatened withdrawal) of material benefits if they refuse sex or use contraceptives against their partner's wishes can act as a powerful inhibitor of their sexual freedom and safe sex practices. ${ }^{22}$

Violence in pregnancy may pose a threat to the life and health of the mother and the fetus. ${ }^{23}$ Physical violence during pregnancy is associated with miscarriage, late entry into prenatal care, stillbirth, premature labor and birth, and low birth weight. ${ }^{24}$ In a study of 400 villages in Pune, India, 16\% of all deaths during pregnancy resulted from partner violence; ${ }^{25}$ partner homicide has also been identified as an important cause of maternal deaths in Bangladesh and in the United States. ${ }^{26}$ And although data from Africa are limited, recorded partner violence was the fourth leading cause of maternal death at Maputo Central Hospital in Mozambique. ${ }^{27}$

Violence may also result from reproductive and sexual health problems and issues. Research in Uganda, South Africa and Zimbabwe has found that women's refusal of sex is often cited as a justification for violence. ${ }^{28}$ In a sample of men interviewed in a workplace in Cape Town, factors significantly associated with sexual violence included involvement in violence outside the home (e.g., brawls or fights in public), alcohol use, multiple sexual partners and conflict over sexual refusal or the perception that their authority had been undermined. ${ }^{29}$ Also, covert contraceptive use may make some women vulnerable to partner violence. ${ }^{30}$ Case studies of women experiencing violence in Zimbabwe suggest that intimate partner violence may be associated with sexual health problems and infertility. ${ }^{31}$ Suspected infidelity is a commonly accepted reason for violence, and several studies document cases of violence by men who discovered that their partner had contracted HIV or another STI. ${ }^{32}$ In six countries in Africa, fear of ostracism and violence in the home is an important reason why pregnant women refuse an HIV test or do not return for their results. ${ }^{33}$

Among South African women receiving antenatal care in Soweto, intimate partner violence is significantly associated with HIV seropostivity. ${ }^{34}$

\section{INTEGRATION OF RESPONSES TO VIOLENCE}

Reproductive health providers are increasingly recognized as playing an active role in helping to identify, support and refer victims of partner violence. ${ }^{35}$ This role may be very important, as many women who have experienced violence will not seek help from the police or support agencies, yet early identification of the problem could help limit the consequences and decrease the likelihood of further victimization.

Several professional medical bodies in industrialized countries have provided guidance for practitioners on intimate partner violence. ${ }^{36}$ In Sub-Saharan Africa, however, there has been limited discussion of the potential role of reproductive health workers. Reproductive health service providers in Africa typically fall into two categories: antenatal care or midwife staff, who offer pre- and postdelivery care; and family planning staff, who provide contraceptives and advice on sexual issues, and who are now being encouraged to offer STI management services. Some public health family planning nurses may also offer counseling services on sensitive issues, such as contraceptive use, STIs and HIV. Although family planning services have long been criticized for neglecting adolescents and men, family planning and antenatal care providers do, nevertheless, cater to a large proportion of sexually active women, many of whom are or will become victims of intimate partner violence.

Demographic and Health Surveys in Sub-Saharan Africa indicate that up to $95 \%$ of women receive some sort of antenatal or family planning care. This contact with the health system provides an important window of opportunity for providers to identify and offer support to women who have experienced violence. Indeed, the involvement of reproductive health providers may be particularly appropriate, given the reproductive consequences of violence and the various reproductive health needs that may put women at increased risk of violence. Furthermore, because reproductive health providers have a long history of dealing with sensitive issues (e.g., sexuality, contraception and sex negotiation) and because there are several initiatives to train them in AIDS counseling, they may become increasingly well equipped to provide support to abused women.

Within any clinic setting providing services on a daily basis (e.g., family planning or antenatal care), it is likely that reproductive health providers come into contact with women who have experienced or are experiencing violence. Some women will disclose abuse or fear of violence, or will report having been raped. Providers also see women who do not openly disclose abuse, but who have physical signs associated with violence (e.g., bruises, lacerations and history of unexplained pregnancy complications). Finally, providers will see women who do not report or present with any problems associated with violence, but who nevertheless are living in a violent relationship.

There is ongoing debate about the extent to which it is feasible for health providers to identify and support women who have experienced violence. The most passive level of activity, which may be appropriate for settings with limited resources, is ensuring that providers do not further vic- 
timize women who report having been abused or raped. At this level, policies and training should focus on ensuring that women are treated sensitively and nonjudgmentally, that the incident is recorded and that women receive appropriate STI treatment or are referred to appropriate services if needed.

A more active approach would be for health providers, during health inquiries, to ask either all women or just those who show signs of ongoing or severe violence about their experiences of violence. To identify women at high risk, it would be necessary for providers to come up with a list of potential indicators of partner violence, such as a history of unexplained injury or maternal bleeding, preterm labor or birth, and fetal injury or death.

Routine questioning necessitates the development of a short module of questions about current or past violence that providers would ask their female clients. Several such modules have been developed, and this approach has been adopted in some industrialized countries and in the International Planned Parenthood Federation-Western Hemisphere's Latin America Program. ${ }^{37}$ These initiatives generally require training for all clinic staff, and necessitate that services for women experiencing intimate partner violence become an integrated component of clinic activity. As well as being a mechanism for support, this level of investment allows providers to better understand whether presenting problems may have been caused by violence, and to gear their provision of services to reflect the specific needs of clients in violent relationships. For example, contraceptive methods such as the injectable are discreet and may be more suitable than condoms or even the pill for women whose partners oppose contraceptive use.

There is evidence that clients of reproductive health services would support such initiatives: For example, $88 \%$ of women attending a community clinic in Cape Town, South Africa, said they would welcome routine screening for violence. ${ }^{38}$ A more in-depth study in the United States found that both abused and nonabused women favored screening for violence by their health providers. ${ }^{39}$ Women emphasized the importance of having providers who understand domestic violence and are well informed, willing to listen and able to provide information on community resources; ${ }^{40}$ also, they thought that reproductive health workers could play an important role by providing emotional support to women and by condemning violence. However, any kind of health service response to violence requires institutions to provide women with confidential and nonjudgmental services. ${ }^{41}$

\section{Changing Attitudes}

Reproductive health providers may hold common misconceptions and stereotypes about women who have experienced partner violence, including the assumption that such women must have done something to warrant violence or that partner violence is not a serious issue. ${ }^{42}$ To ensure that women are not further victimized or blamed during the process of consultation and disclosure, reproductive health staff must first confront their own biases, misconceptions and fears about violence against women.

Confronting and changing negative or blaming attitudes is a key challenge, particularly as such attitudes may be entrenched among health workers in some settings. ${ }^{43}$ As violence against women is driven by gender and power inequalities, this fundamentally requires providers to challenge issues of power and abuse in their own lives. ${ }^{44}$ In practice, only some workers may be interested, sensitive and skilled enough to effectively deal with gender violence; even so, those staff should be recognized and supported.

A further impediment lies in an entrenched ethos of institutional hierarchies, and the ways management attitudes and cultures influence the extent to which providers can put new skills into practice. For example, without institutional support, some nurses may not be able to put their training into practice. ${ }^{45}$

\section{Space, Time and Confidentiality}

Privacy and confidentiality are paramount considerations for working with women who have experienced violence. Women are unlikely to disclose their experiences if they do not feel confidentiality will be maintained, and women may be put at risk of further violence if their reports are overheard. Maternal and child health and family planning providers have not always been able to ensure privacy. ${ }^{46}$ Where examination rooms are screened only with a curtain, for example, or where initial screenings take place in public, women will be reluctant to disclose violence. In addition, confidentiality may be particularly difficult in rural areas, where providers are likely to live in the same communities and may know both the woman and her partner.

Time constraints are another challenge. Often, health workers do not have much time to spend with individual clients. ${ }^{47}$ This may mean that even if a woman discloses violence, her provider may not be able to spend a sufficient amount of time to provide her an adequate response. Allowing providers the flexibility to spend additional time with clients when needed may be an important issue in establishing trust and confidence between them.

\section{Shaping a Pragmatic Response}

Despite clear areas for potential intervention, there are few examples of serious efforts by reproductive health providers to address intimate partner violence in Africa. The dearth of operational linkage between violence and reproductive health programs at the national level results both from the inherent delay between international attention and national action, and from difficulties in developing strategic plans that allow global rhetoric to be acted upon. Even in industrialized countries where resources are not so constrained, there is debate about what form and level of health sector response to intimate partner violence may be appropriate and feasible. ${ }^{48}$

A rush to add domestic violence services to reproductive health activities could lead to insensitive approaches that further jeopardize women's safety. It is far preferable that a considered, sustainable and context-specific approach be developed in which the pros and cons of different forms 
TABLE 1. Ways of addressing inimate partner violence, according to type of provider

\begin{tabular}{|c|c|c|c|}
\hline Nurse/health worker & Clinic/care setting & Hospital & Ministry of Health \\
\hline $\begin{array}{l}\text { Being informed about the types, } \\
\text { extent and underlying causes } \\
\text { of violence }\end{array}$ & $\begin{array}{l}\text { Developing policies on } \\
\text { violence against women }\end{array}$ & $\begin{array}{l}\text { Accepting referrals and } \\
\text { acting as a reference } \\
\text { point for clinic/case }\end{array}$ & $\begin{array}{l}\text { Publicly condemning violence } \\
\text { against women }\end{array}$ \\
\hline $\begin{array}{l}\text { Screening for abuse during } \\
\text { reproductive health consultations }\end{array}$ & $\begin{array}{l}\text { Ensuring private space is } \\
\text { available when needed } \\
\text { for consultations }\end{array}$ & $\begin{array}{l}\text { facilities implementing } \\
\text { policies to address } \\
\text { violence against women }\end{array}$ & $\begin{array}{l}\text { Being informed about types } \\
\text { of violence, underlying causes } \\
\text { and consequences }\end{array}$ \\
\hline $\begin{array}{l}\text { Supporting women emotionally by } \\
\text { validating their experiences, and by } \\
\text { being nonjudgmental and willing } \\
\text { to listen }\end{array}$ & $\begin{array}{l}\text { Displaying posters/leaflets } \\
\text { condemning violence against } \\
\text { women }\end{array}$ & $\begin{array}{l}\text { Developing protocols on the } \\
\text { management of rape, child } \\
\text { sexual abuse and other forms } \\
\text { of violence }\end{array}$ & $\begin{array}{l}\text { Supporting the development } \\
\text { of policies and protocols on } \\
\text { different forms of violence } \\
\text { against women }\end{array}$ \\
\hline $\begin{array}{l}\text { Providing appropriate clinical care } \\
\text { (e.g., emergency contraception, } \\
\text { pregnancy testing, and STI/HIV } \\
\text { testing and treatment) }\end{array}$ & $\begin{array}{l}\text { Supporting staff interested in } \\
\text { helping women who have } \\
\text { experienced violence, and } \\
\text { promoting staff access to } \\
\text { appropriate training }\end{array}$ & $\begin{array}{l}\text { Ensuring staff are appropriately } \\
\text { trained to handle rape, child } \\
\text { sexual abuse and other forms } \\
\text { of violence }\end{array}$ & $\begin{array}{l}\text { Incorporating specialized } \\
\text { curricula on violence against } \\
\text { women into health worker } \\
\text { training }\end{array}$ \\
\hline $\begin{array}{l}\text { Documenting the medical } \\
\text { consequences of violence }\end{array}$ & $\begin{array}{l}\text { Supporting staff who have } \\
\text { experienced partner violence }\end{array}$ & $\begin{array}{l}\text { Developing statements on the } \\
\text { unacceptability of violence }\end{array}$ & $\begin{array}{l}\text { Monitoring and evaluating } \\
\text { initiatives to address intimate } \\
\text { partner violence }\end{array}$ \\
\hline $\begin{array}{l}\text { Maintaining confidentiality } \\
\text { Referring women to community } \\
\text { services and resources, if they exist }\end{array}$ & $\begin{array}{l}\text { Creating links with other local } \\
\text { organizations working to } \\
\text { address gender violence }\end{array}$ & $\begin{array}{l}\text { Supporting staff interested in } \\
\text { helping women who have } \\
\text { experienced violence, and } \\
\text { promoting staff access to } \\
\text { appropriate training }\end{array}$ & $\begin{array}{l}\text { Being active in multisectoral } \\
\text { initiatives on intimate partner } \\
\text { violence }\end{array}$ \\
\hline & & $\begin{array}{l}\text { Being active in multisectoral } \\
\text { initiatives on intimate partner } \\
\text { violence }\end{array}$ & \\
\hline
\end{tabular}

of intervention are carefully assessed. This must draw upon the experience and expertise of both reproductive health workers and activists against violence. In particular, some of the regional alliances that helped propel the issue onto the global agenda may provide a key asset in the development of appropriate local, national and regional initiatives. ${ }^{49}$ Table 1 outlines the range of responses possible at different levels to provide a comprehensive response to violence.

\section{Provider Skills and Training}

If reproductive health service providers are to be trained to help abused women, appropriate and context-specific aims need to be identified. Given the many barriers, policies should be based on realistic expectations about what such an initiative may achieve.

At a minimum, reproductive health providers should give women key messages about the unacceptability of violence, and ensure that women are receiving appropriate health services and are aware of the available forms of support, if they would like to take further action. Where providers have more time or resources, they could become more involved in counseling, providing ongoing support and routinely enquiring about violence.

Expectations, however, need to be realistic. Throughout Sub-Saharan Africa, the number of trained counselors at health facilities generally remains small, and in many settings, there are ongoing doubts surrounding the efficacy of reproductive health counseling. ${ }^{50}$ Many studies report providers' insensitivity and poor interpersonal skills as a barrier to health seeking behavior. ${ }^{51}$ Nevertheless, in Ghana, South Africa and Zimbabwe, among others, considerable efforts by individual staff to support women in difficult sit- uations often have been noted. ${ }^{52}$ The way forward may be to identify and support individual health providers who are already committed to providing support to abused women.

The development of strategies for health professionals needs to be approached with care. Western models for counseling and support may not be appropriate, and potential country-specific adaptations or models need to be considered. Initiatives should involve and build on the experiences of local and regional women's organizations, which may have substantial experience providing domestic violence services ${ }^{53}$ and may already have strong connections with legal and other forms of support.

The current widespread attention being given to HIV/AIDS prevention programs, including investment in health workers' counseling skills, may offer a significant opportunity for the inclusion in counseling training of skills to discuss intimate partner violence. To support women who have experienced violence, it is important that providers have adequate time to talk with clients. Without the time and privacy for adequate provider-client interaction, women will not benefit, and some could be exposed to greater risk and distress. If counseling is to be beneficial to women, it needs to be done well; otherwise, it may be better to refer clients to specialized providers, if they exist.

\section{Improving Documentation}

Given the ongoing relationship that some providers have with clients, reproductive health workers may be in a position to document and testify to women's experiences of violence. The systematic medical documentation of reports of violence can be critical for women who wish to press charges against their attacker. In addition, clear and prompt 
documentation can reduce delays in service delivery: In Zimbabwe, for example, some rape survivors were denied abortions because of documentation delays. ${ }^{54}$

At tertiary levels of care, health ministries and hospitals should develop standard protocols for documenting reports of partner violence, rape and sexual abuse. In Zimbabwe, for example, hospitals already have protocols for managing rape, including STI screening, provision of emergency contraception and access to abortion. ${ }^{55}$ South Africa is currently developing a policy for handling rape cases, including the provision of postexposure HIV prophylaxsis. ${ }^{56}$ Procedures to respond to violence should also offer sufficient guidance on how to appropriately document cases. For example, medical affidavits may require an assessment of the severity of violence, but the criteria for this are often unclear. ${ }^{57}$

Due care is needed, however, to ensure that documentation of violence against women does not compromise confidentiality. For example, women's safety could be jeopardized if integrated reporting forms are readily accessible to all clinic staff. The ethical and safety issues involved with services for abused women render it imperative that responding to and documenting violence be done with the utmost sensitivity.

\section{Intersectoral Collaboration and Referral}

Women who have experienced violence may need to make contact with a number of agencies, such as the police and social welfare. A coherent response to partner violence should not be confined to the clinical setting, but should coordinate different areas of service provision and support; ultimate responsibility lies with the program planners and managers, although health care providers should also be aware of the need for broader links. When facilities cannot themselves provide services to abused women but wish to refer them to other providers, the logistics of referrals need to be properly streamlined to minimize the number of steps it takes for women to receive help.

One approach to addressing such problems is to identify a "buddy" or advocate-such as a woman who has already left a violent situation and is familiar with the available services-to accompany women. Another is to identify key persons in each agency to whom a client can be directly referred. People in the different agencies could meet to review cases and learn how to strengthen and revise procedures. Where linkage to organizations working against violence is difficult or where nongovernmental organizations' activities are weak, Heise suggests identifying sympathetic community leaders, such as chiefs and clergy, who could help arrange referrals to appropriate support. ${ }^{58}$

In general, working with diverse organizations and structures-each with its own priorities, institutional cultures and practices-can be frustrating and slow. ${ }^{59}$ Nevertheless, there are examples of successful initiatives: For example, Ghana's police force has just established a female police corps as part of a national campaign against gender-based violence, ${ }^{60}$ and in Namibia, the Ministry of Health and Social Services has established 13 Women and Child Protec- tion Units, one-stop centers that provide health, legal and counseling services to abused women. ${ }^{61}$

\section{CONCLUSIONS}

In Sub-Saharan Africa, as elsewhere, physical and sexual partner violence is widespread, and has strong implications for women's reproductive health. Despite the broadened mandates at the international level, however, few initiatives are in place to integrate a response to violence into reproductive health services.

Still, pragmatic responses are possible. Even relatively low-resource initiatives can make a difference by trying to ensure that women's experiences are validated and that women are not judged or blamed for the violence they report. In settings with more resources, service providers have more opportunities to better understand the role of violence in the health problems women bring to them, to gear services to specific needs of women who have experienced violence and, where possible, to refer these women to appropriate services. Although the challenges are many, it is imperative that the issues of gender inequality and violence be challenged head on if the promise of women's reproductive rights is to be fulfilled.

\section{REFERENCES}

1. Heise L, Ellsberg M and Gottemoeller M, Ending violence against women, Population Reports, 1999, Series L, No. 11.

2. Mayhew SH and Watts C, Global rhetoric vs. individual realities: linking violence against women and reproductive health, in: Lee K, Fustukian S and Buse K, eds., Health Policy in a Globalising World, Cambridge, UK: Cambridge University Press, 2002.

3. Heise L, Violence against women: global organizing for change, in: Edleson JL and Eisikovitz ZC, eds., Future Interventions with Battered Women and Their Families, Thousand Oaks, CA, USA: Sage, 1996, pp. 7-33; and García-Moreno C and Watts C, Violence against women: its importance for HIV/AIDS prevention, AIDS, 2000, 14(Suppl. 3):253265.

4. Krug EG et al., World Report on Violence and Health, Geneva: World Health Organization (WHO), 2002.

5. WHO, Multi-Country Study on Women's Health and Life Events Final Core Questionnaire (Version 9.9), Geneva: WHO, 2002.

6. Krug EG et al., 2002, op. cit. (see reference 4).

7. Krug EG et al., 2002, op. cit. (see reference 4); Koenig M et al., Domestic violence in rural Uganda: evidence from a community-based study, Bulletin of WHO, 2003, 81(1):53-60; Watts C and Zimmerman C, Violence against women: global scope and magnitude, Lancet, 2002, 359(9313):1232-1237; and Kishor S and Johnson K, Profiling Domestic Violence: A Multi-Country Study, Calverton, MD, USA: ORC Macro, 2004.

8. Watts C et al., Withholding of sex and forced sex: dimensions of violence against Zimbabwean women, Reproductive Health Matters, 1998, 6(12):57-65; and Gossaye Y et al., Women's Health and Life Events Study in rural Ethiopia, Ethiopian Journal of Health Development, 2003, 17 (second special issue):2-50.

9. Gossaye Y, 2003, op. cit. (see reference 8).

10. Watts C et al., 1998, op. cit. (see reference 8); Jewkes R et al., He Must Give Me Money, He Mustn't Beat Me: Violence Against Women in Three South African Provinces, Technical Report, Pretoria, South Africa: Medical Research Council, 1999; and Campbell JC, García-Moreno C and Sharps $\mathrm{P}$, Abuse during pregnancy in industrialized and developing countries, Violence Against Women, 2004, 10(7):770-789.

11. Gossaye Y, 2003, op. cit. (see reference 8).

12. Jansen HAFM et al., Interviewer training in the WHO multi- 
country study on women's health and domestic violence, Violence Against Women, 2004, 10(7):831-849.

13. Campbell JC, Health consequences of intimate partner violence, Lancet, 2002, 359(9314):1331-1336.

14. Heise L, Ellsberg M and Gottemoeller M, 1999, op. cit. (see reference 1); and Campbell JC, 2002, op. cit. (see reference 13).

15. García-Moreno C and Watts C, 2000, op. cit. (see reference 3) Maman S et al., Intersection of HIV and violence: directions for future research and interventions, Social Science $\&$ Medicine 2000, 50(4):459478; and Campbell JC, 2002, op. cit. (see reference 13).

16. Campbell JC, Abuse during pregnancy: progress, policy and potential, American Journal of Public Health, 1998, 88(2):185-186.

17. Dixon-Mueller R, The sexuality connection in reproductive health, Studies in Family Planning, 1993, 24(5):269-282; Ezeh CA et al., The influence of spouses over each other's contraceptive attitudes in Ghana, Studies in Family Planning, 1993, 24(3):163-173; Chibwana T et al., Male involvement: the missing dimension in promoting child spacing, Malaw Medical Journal, 1993, 9(1):18-30; Adongo P et al., Cultural factors constraining the introduction of family planning among the KassenaNankana of Northern Ghana, Social Science \& Medicine, 1997, 45(12): 1789-1804; and Bawah AA et al., Women's fears and men's anxieties: the impact of family planning on gender relations in Northern Ghana, Studies in Family Planning, 1999, 30(1):54-66.

18. Ellsberg M et al., Domestic violence and emotional distress among Nicaraguan women: results from a population-based study, American Psychologist, 2000, 54(1):30-36

19. Ibid.; and Kishor S and Johnson K, 2004, op. cit. (see reference 7).

20. Jewkes R et al., 1999, op. cit. (see reference 10).

21. Blanc A et al., Negotiating Reproductive Health Outcomes in Uganda, Calverton, MD, USA: Macro International and Makerere, Uganda: Institute of Statistics and Applied Economics, Makerere University, 1996 and Njovana E and Watts C, Gender violence in Zimbabwe: a need for collaborative action, Reproductive Health Matters, 1996, 4(7):45-53.

22. Adongo P et al., 1997, op. cit. (see reference 17); Ankomah A, Condom use in sexual exchange relationships among young, single adults in Ghana, AIDS Education Preview, 1998, 10(4):303-316; Watts C et al., 1998, op. cit. (see reference 8); Jewkes R et al., 1999, op. cit. (see reference 10); and Koenig M et al., 2003, op. cit. (see reference 7).

23. Pearlman MD, Tintinally JE and Lorenz RP, Blunt trauma during pregnancy, New England Journal of Medicine, 1990, 323(23):1609-1603 Jejeebhoy SJ, Association between wife beating and fetal death: impressions from a survey in rural India, Studies in Family Planning, 1998, 29(3):300-308; and Parsons MA and Harper LH, Violent maternal death in North Carolina, Obstetrics \& Gynaecology, 1999, 94(9):990-993.

24. Krug EG et al., 2002, op. cit. (see reference 4).

25. Gantra BR et al., Too far, too little, too late: a community based casecontrol study of maternal mortality in rural west Maharashtra, India, Bulletin of the World Health Organization, 1998, 76(6):591-598.

26. Fauveau V et al., Causes of maternal mortality in rural Bangladesh, 1976-1985, Bulletin of the World Health Organization 1988, 66(5):643651; and Harper M and Parsons L, Maternal deaths due to homicide and other injuries in North Carolina: 1992-1994, Obstetrics $\varepsilon$ Gynecology, 1997, 94(6):990-993.

27. Krug EG et al., 2002, op. cit. (see reference 4).

28. Blanc A et al., 1996, op. cit. (see reference 21); and Jewkes R et al., 1999, op. cit. (see reference 10).

29. Abrahams N et al., Sexual violence against intimate partners in Cape Town: prevention and risk factors reported by men, Bulletin of the World Health Organization, 2004, 82(5):330-337.

30. Blanc A et al., 1996, op. cit. (see reference 21); Rao V, Wife-beating in rural South India: a qualitative and econometric analysis, Social Science E Medicine, 1997, 44(8):1169-1180; and García-Moreno C and Watts C, 2000, op. cit. (see reference 3)

31. Njovana E and Watts C, 1996, op. cit. (see reference 21).

32. Fischbach RL and Herbert B, Domestic violence and mental health: correlates and conundrums within and across cultures, Social Science E Medicine, 1997, 45(8):1161-1176; Wingood G, DiClemente R and Raj A, Adverse consequences of intimate partner abuse among women in non-urban domestic violence shelters, American Journal of Preventive Medicine, 2000, 19(4):270-275.

33. Krug EG et al., 2002, op. cit. (see reference 4)

34. Dunkle KL et al., Gender-based violence, relationship power and risk of HIV infection in women attending antenatal clinics in South Africa, Lancet, 2004, 363(9419):1415-1421

35. García-Moreno C, Dilemmas and opportunities for an appropriate health-service response to violence against women, Lancet, 2002, 359(9316):1509-1514.

36. Council on Scientific Affairs, American Medical Association, Violence against women: relevance for medical practitioners, Journal of the American Medical Association, 1992, 267(23):3184-3195; American College of Obstetricians and Gynecologists (ACOG), Domestic violence, ACOG Technical Bulletin, Washington, DC: ACOG, 1993, No. 209; British Medical Association (BMA), Domestic Violence: A Health Care Issue, London: BMA, 1998; and Royal College of Midwives, Domestic Abuse in Pregnancy, Position Paper, London: Royal College of Midwives, 1997, No. 19

37. International Planned Parenthood Federation-Western Hemisphere, The link between gender-based violence and sexual and reproductive health, Basta!, 2000, <http://www.ippfwhr.org/publications/serial_ issue_e.asp?PubID=10\&SerialIssuesID=2>, accessed Sept. 28, 2004.

38. Kim J, Health sector initiatives to address domestic violence against women in Africa, in: Proceedings of the Health Care Strategies for Combatting Violence Against Women in Developing Countries Meeting, Ghent, Belgium, August 1999, Ghent, Belgium: International Centre for Reproductive Health, University of Ghent, 1999

39. McNutt L et al., Reproductive violence screening in primary care: perspectives and experiences of patients and battered women, Journal of the American Medical Association, 1999, 54(2):85-90.

40. Gielen AC et al., Women's opinions about domestic violence screening and mandatory reporting, American Journal of Preventive Medicine 2000, 19(4):279-286.

41. García-Moreno C, 2002, op. cit. (see reference 35).

42. Kim J and Motshei M, "Women enjoy punishment": attitudes and experiences of gender violence among primary health care nurses in rural South Africa, Social Science \& Medicine, 2002, 54(8):1243-1254.

43. Jewkes R, Abrahams N and Mvo Z, Why do nurses abuse patients? reflections from South African obstetrics services, Social Science $E$ Medicine, 1998, 47(11):1781-1795.

44. García-Moreno C, 2002, op. cit. (see reference 35).

45. Mayhew SH, Integration of STI services into FP/MCH services: health service and social contexts in rural Ghana, Reproductive Health Matters, 2000, 8(16):112-124; and Mayhew SH et al., Integrating component services for reproductive health: the problem of implementation, Studies in Family Planning, 2000, 31(2):151-162

46. Population Council, Setting the African Agenda: Report of an African Region Conference on Integration of STI/HIV Services into MCH/FP Services, New York: Population Council, 1995; Kisubi W et al., An African Response to the Challenge of Integrating STD/HIV/AIDS Services into Family Planning Programs, Watertown, MA, USA: Pathfinder International, 1997; and Mayhew SH, Health Care in Context, Policy into Practice: A Policy Analysis of Integrating STD/HIV and MCH/FP Services in Ghana, London: London School of Hygiene and Tropical Medicine, 1999.

47. Population Council, 1995, op. cit. (see reference 46); Kisubi W et al., 1997, op. cit. (see reference 46); and Maggwa BN and Askew I, Integrating STI/HIV Management Strategies into Existing $\mathrm{MCH} / \mathrm{FP}$ Programs: Lessons from Case Studies in East and Southern Africa, New York: Population Council, 1997.

48. Cole TB, Is domestic violence screening helpful? Journal of the American Medical Association, 2000, 284(5):551-553; and Ramsey J etal., Should health professionals screen women for domestic violence? systematic review, British Medical Journal, 2002, 325(7359):314-326.

49. Mayhew SH and Watts C, 2002, op. cit. (see reference 2). 
50. Population Council, 1995, op. cit. (see reference 46); Kisubi W et al., 1997, op. cit. (see reference 46); and Maggwa BN and Askew I, 1997, op. cit. (see reference 47).

51. McCauley AP et al., Opportunities for women through reproductive choice, Population Reports, 1994, Series M, No. 12; and Kim YM et al., Quality of counselling of young clients in Zimbabwe, East African Medical Journal, 1997, 74(8):514-518.

52. Mayhew SH, 1999, op. cit. (see reference 46); and Njovana E and Watts C, 1996, op. cit. (see reference 21).

53. Women in Law and Development in Africa (WiLDAF), Annual Report, 1995, Harare, Zimbabwe: WiLDAF, 1996; and Njovana E and Watts C, 1996, op. cit. (see reference 21).

54. Watts C and Ndlovu M, Violence against women in Zimbabwe: strategies for action, Harare, Zimbabwe: Musasa Project, 1997.

55. Ibid.

56. Kim J, London School of Hygiene and Tropical Medicine, London, personal communication, Oct. 20, 2002.
57. Watts C et al., 1997, op. cit. (see reference 54).

58. Heise L, 1996, op. cit. (see reference 3).

59. Stewart S, Working the system: sensitizing the police to the plight of women, in: Schuler M, ed., Freedom from Violence: Women's Strategies from Around the World, New York: United Nations Development Fund for Women, 1992

60. Reproductive Mother and Child Health Unit, Ghana Ministry of Health, Annual Report, 2003, Accra, Ghana: Ministry of Health and Social Services, 2004.

61. January E, Ministry of Health and Social Services, Windhoek, Namibia, personal communication, Aug. 3, 2004.

Author Contact: charlotte.watts@lshtm.ac.uk

\section{Acknowledgments}

The authors are grateful to Lori Heise for comments on an earlier draft. 